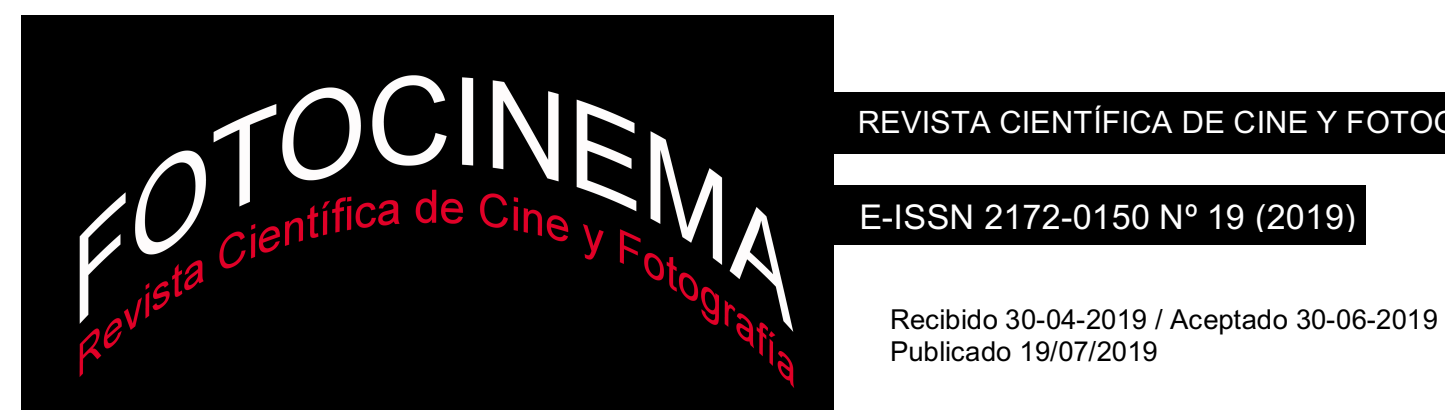

\title{
Puntos ciegos: tiempo, memoria y dimensión cinemática de la relación fotografía-pintura
}

\author{
Blind points: Time, memory and cinematic dimension of the \\ photography-painting relationship
}

\section{Resumen:}

\author{
Ricardo González-García \\ Universidad de Cantabria, España \\ gonzalezgr@unican.es
}

El inconsciente óptico que estudian Walter Benjamin y Rosalind Krauss implica una instantaneidad visual proveniente del medio fotográfico, pues su resultado icónico aporta datos que pueden llegar a escaparse a la visión humana. Ello instaura una sublimación diferenciada que nubla el enfoque cristalino de los regímenes escópicos de la modernidad, pero envuelve a las vanguardias artísticas del siglo XX en una experimentación plástica sin precedentes. Partiendo de la fotografía -específicamente de las fotografías desenfocadas y las cronofotografías- y de su influencia en la pintura, se alude en el presente artículo a determinados "puntos ciegos" como pérdidas de foco entre ambos medios, los cuales pueden llevar su hibridación. Correspondencias necesarias, no obstante, que desde el concepto de index y punctum conducen a analizar cuestiones específicas del cine que Gilles Deleuze investiga al desarrollar el concepto de imagen-tiempo y el de imagen-movimiento, los cuales, vistos desde la perspectiva de un tipo de pinturas que toma la fotografía como referente, nos llevan a remitir a cuestiones relacionadas con la memoria y la dimensión cinemática. Tras estas reflexiones, finalmente se demuestra que la borrosidad de la imagen ayuda a descubrir ciertas claves del nuevo régimen escópico al que nos transporta la imagen digital, así como a descubrir "puntos ciegos" de mayor alcance que se relacionan con la construcción de la mirada del momento presente y la tectónica epistemológica.

\begin{abstract}
:
The optical unconscious studied by Walter Benjamin and Rosalind Krauss implies a visual instantaneity that comes from the photographic medium, since its iconic outcome contributes data that can escape to the human vision. This establishes a differentiated sublimation that clouds the crystalline approach of the scopic regimes of modernity, but envelops the artistic vanguards of the 2oth century in an unprecedented plastic experimentation. Starting from photography -specifically from out-of-focus photographs and chronophotographs- and from their influence on painting, this article is referred to certain "blind spots" as loss of focus between both media, that can also lead to hybridize them. Necessary corrections, however, that from the concept of index and punctum lead us to analyze specific questions of the cinema that Deleuze research when developing the concept of image-time and the image-movement, which, seen from the perspective of a type of paintings that takes photography as a reference, lead us to refer to issues related to memory and the cinematic dimension. After these reflections, it is finally shown that the blurring of the image helps to discover certain keys of the new scopic regime to which the digital image transports us, as well as to discover "blind spots" of greater scope that are related to the construction of the gaze of the present moment and epistemological tectonics.
\end{abstract}

Palabras clave: punto ciego; fotografía; pintura; memoria; tiempo; movimiento.

Key words: Blind Point; Photography; Painting; Memory; Time; Motion. 


\section{Introducción}

El punto ciego es la parte de la retina donde surge el nervio óptico. Al carecer de células sensibles a la luz (células fotoreceptoras como son los conos y los bastones), no posee sensibilidad óptica. Aun así, no percibimos esa zona donde la imagen desaparece, pues esta es completada o compensada con la información que le confiere un segundo punto de vista. Tener un mayor campo de visión, percibir la profundidad y que la falta de información se compense, tal y como hemos indicado, son algunas de las funciones que posee la visión binocular o estereoscópica. De un modo metafórico, se puede trasladar aquí ese fenómeno de naturaleza biológica a la relación existente entre la fotografía y la pintura, como medios expresivos que, implicando formas de representar y mirar la realidad, también pueden complementarse o compensarse cuando aparecen relacionados o, incluso, hibridados. Pero, además, una vez establecida dicha correspondencia, también se puede aludir a la vinculación existente entre esta manera de relacionar ambos medios y cómo se contemplan dependiendo del momento histórico, el determinismo tecnológico y el régimen escópico característicos del mismo.

Partir, por tanto, de la relación que comienza a establecerse entre pintura y fotografía a causa de la aparición de esta última, es referirse a cómo cambia la forma de mirar del artista y del espectador a partir de la presencia del dispositivo técnico que desarrolla. Desde este, experimentar, por ejemplo, con el objetivo o las técnicas de revelado para desenfocar la imagen, nos traslada a comentar una poética donde memoria y tiempo se funden, la cual será aprovechada por muchas manifestaciones pictóricas. En cambio, desde la sofisticación que confiere la tecnología que desarrolla la fotografía, pero desde una intención contraria, esta también busca estudiar el movimiento a través de ráfagas de disparos instantáneos, lo cual también supondrá una influencia notable para cierto tipo de pintura que pretende transmitir una dimensión cinemática.

En un juego cruzado de referencialidades, la presente investigación delata la existencia de ciertos "puntos ciegos" existentes en la relación entre la pintura y 
la fotografía a partir del nacimiento de esta última. Pues, más allá de ser medios que en un principio podrían verse como rivales, nos trasladan al análisis de su complementariedad. Asimismo, es crucial observar cómo la evolución de los dos medios, y los entrecruzamientos que entre ambos se van generando, también se transforma el régimen escópico.

Realizar este cometido supone comenzar analizando los inicios pictorialistas de la fotografía para comprobar cómo, a medida que cada medio busca su autonomía, se siguen estableciendo toda una red de intercambios semióticos o semánticos entre las imágenes que cada uno de ellos genera. En ese sentido, los ejemplos aquí ofrecidos serán esclarecedores para corroborar una relación mediática que aún hoy continúa. Empero, dada la amplitud del tema tratado, las limitaciones propias del presente formato nos llevan a sintetizar todo el proceso para demostrar que el estudio comparado de ambos nos dirige a una visión enriquecida del quehacer plástico-visual que revitaliza la interrelación mediática. Así como a comprobar la existencia de "puntos ciegos" en esta relación, los cuales son extensibles al modo de mirar del momento presente y, por tanto, a la conformación de la epistemología.

\section{El inicio de los trasvases estéticos pintura-fotografía}

Antes de la aparición de la fotografía a mediados del siglo XIX, la pintura representa el medio de reproducción icónico por excelencia, el cual, en amable diálogo estético, se relaciona con otros medios como el grabado, la ilustración o el cartel, compartiendo con estos una misma pulsión táctil devenida de un carácter quirográfico común. En cambio, la fotografía supone una invención que recurre a la creación de imágenes mediante un procedimiento mecánico. En principio, la función de esta herramienta (analógica) es obtener una representación a partir de un motivo escogido, lo cual conlleva situar y preparar la cámara, tomar la foto y luego proceder, mediante un proceso químico, a revelar la imagen obtenida sobre un soporte. Este método instantáneo de conseguir imágenes, que los coetáneos a su invención pudieron considerar como truco de magia, de algún modo entra en conflicto con los medios quirográficos mencionados, pues de forma 
resolutiva la fotografía les arrebataba ciertos géneros representativos que habían defendido tradicionalmente. Esta situación por un lado lleva a discrepancias entre defensores y detractores del nuevo medio, pero también, por otro lado, supone el inicio de otra forma de mirar en el espectador, y de opinar sobre lo que este considera como artístico.

Entre los que comienzan a practicar con el nuevo medio que supone la fotografía también existen división de opiniones. Por una parte, están los que consideran que la fotografía ha de limitarse a registrar con la mayor objetividad posible la realidad, estimando así su valor documental, y por otra, quienes opinan que la fotografía necesita de tanta intervención como la pintura para poder ser considerada arte. Para alcanzar este último requisito, se recurre a acciones que van desde la búsqueda del modelo adecuado, la iluminación precisa y el cuidado de detalles compositivos, a la intervención posterior en el revelado del negativo para recrear -a pesar de partir de una matriz común- imágenes únicas. A este tipo de creadores de fotografías que emulan las pautas de la tradición pictórica, copiándola literalmente en muchas ocasiones, se los denomina pictorialistas. Este primer trasvase estético que en este caso realizó la fotografía de la pintura acabará, como veremos, en un razonable entendimiento.

El pictorialismo, como movimiento artístico en sí mismo, evoluciona desde el año 1880 hasta la Segunda Guerra Mundial. Aun así, y a pesar de este supuesto fin, existen muchos ejemplos que nos permiten notar la traza que dejó la tradición pictórica si se examinan las formas en que algunos fotógrafos, desde las primeras vanguardias a la actualidad, conciben sus creaciones. Conviene recordar que, previa al movimiento pictorialista, fue la obra Pictorial effect in photography. Being hints on composition and chiarooscuro for photographers (1869) la que define, desde un punto de vista teórico, sus pautas fundamentales. En ella, Henry Peach Robinson explica, entre otros procedimientos, el positivado combinado como "un método que permite al fotógrafo representar objetos en distintos planos dentro de un foco apropiado, y mantener la verdadera relación lineal y atmosférica de distintas distancias" (Fontcuberta, 2003, p. 78). Tras las bases que establece este 
autor, el pictorialismo realmente comienza tras aparición del ensayo Naturalistic Photography (1889), de Peter Henry Emerson, gran defensor del uso de fórmulas pictorialistas en contra de quienes opinan que la fotografía ha de limitarse a reproducir la naturaleza.

En su transitar como movimiento artístico, el pictorialismo adquiere gran relevancia en Austria, Francia, Inglaterra y posteriormente en Estados Unidos, incorporando las maneras de proceder pictóricas de diversas escuelas de los lugares donde recala. Casi todas estas manifestaciones pictorialistas se muestran cercanas a las teorías de la pintura del romanticismo. En contra de aquella parte de la fotografía dedicada al testimonio documental, el pictorialismo representa una búsqueda encaminada a explotar las posibilidades plásticas de la técnica fotográfica como vía para llegar a un lenguaje artístico propio.

Aunque se pueden encontrar muchos ejemplos que testimonian la influencia que la pintura ejerció en las primeras tomas fotográficas, es durante la etapa impresionista cuando el pictorialismo halla una cautivadora inspiración. La resolución desdibujada, emborronada o diluida característica de las obras de este movimiento pictórico seduce a practicantes de la fotografía, quienes tratan de imitar dichas cualidades provocando intencionados desenfoques en la óptica, de modo que las fotografías resultantes ofrezcan cierto efecto floue (borroso, desvaído, movido, vago). Entre los fotógrafos que ahondan en la consecución de esta sensación, destacan Robert Demachy y Constant Puyo, entre otros. Los motivos en los que se manifiesta esta falta de nitidez en su mayoría son paisajes abrumadoramente atmosféricos, o borrosos retratos que parecen sumir al personaje en una misteriosa niebla que lo indiferencia. A imitación de las clásicas composiciones del mundo de la pintura, este tipo de concepción fotográfica busca en todo momento la alegoría.

Para lograr estos resultados, técnicamente el fotógrafo recurre a la colocación de filtros en la lente de la cámara, o a la utilización de los denominados “objetivos de artista”: lentes imperfectas que, no adaptándose si quiera en ocasiones a la cámara, consiguen producir errores inducidos y aberraciones. Pero la mayor parte de las manipulaciones se producen cuando se revela y 
positiva la imagen, mediante la técnica del carbón, el bromóleo, la goma bicromatada o el añadido de pigmentos a las emulsiones sobre papeles de diferente naturaleza, considerando "el negativo como mero paralelo al fondo de un óleo, mientras que el trabajo que realizaban en el positivo era para ellos la auténtica actividad creadora” (Loup Sougez, 1998, p. 189).

Sintetizando, tras la argumentación de Emerson de que la manualidad que puede ser añadida a la fotografía eleva a sus autores al estatus de artistas difuminando prejuicios-, el objetivo que persigue el pictorialismo es distanciarse de la fotografía documental que practican los profesionales, así como los aficionados que se suman a partir de la comercialización de la cámara Kodak $\mathrm{n}^{\mathrm{o}} 1$ en 1888. Este singular distanciamiento supone el comienzo de la discusión acerca de la consideración de la fotografía como obra de arte, y de la reflexión en torno a su técnica y a la originalidad que esta puede aportar (Fontcuberta, 2003, p. 78). En aras de una asimilación de expresiones fotográficas que enfatizan su plasticidad, y tras un primer período donde las manipulaciones a veces llegan a la extravagancia, le sigue uno de mayor purismo y austeridad. Esta evolución, asimismo, es posible gracias a la creación de asociaciones que realizan periódicamente exposiciones que acompañan de manifiestos teóricos y técnicos, a fin de mostrar los avances en su campo. En esta progresión gradual, cabe destacar la prestigiosa figura de Alfred Stieglitz, quien, reivindicando en todo momento que la fotografía se considerara como una manifestación artística, introduce a través del pictorialismo cierta pátina de la historia europea en un país aún joven como Estados Unidos.

\section{Lo pictórico en la fotografía y lo fotográfico en la pintura}

La existencia de lo que Étienne Souriau (1986) denominó como “correspondencia de las artes”, lleva a establecer no solo relaciones estéticas, sino procesos plásticos donde los medios expresivos pueden llegar a hibridarse. Una explícita aceptación de este fenómeno la podemos encontrar claramente expresada por Theodor W. Adorno (2008, p. 379) en 1966: “en el desarrollo reciente se confunden las fronteras entre los géneros artísticos, o 
mejor dicho: sus líneas de demarcación se entrelazan”. Esta interacción amplía el objeto de estudio a un ingente número de expresiones pictóricofotográficas o fotográfico-pictóricas heterogéneas que habrá que interpretar para comprender sus procesos de entrelazamiento.

Esta mirada interdisciplinar supone una apertura del campo de la investigación, pues dicho fenómeno nos empuja a tratar de discernir entre relaciones interestéticas e intersemióticas que, a su vez, enlazan con distintos movimientos socioeconómicos y políticos, culturales y científicos, sobre los que el arte reflexiona desde sus diferenciadas concepciones y migraciones estéticas. Este terreno convergente implica, desde la capacidad de hibridación existente entre la pintura y la fotografía, atender a cierta indexación, si tomamos en cuenta la teoría clasificatoria del semiólogo Charles Sanders Peirce (1987). Pues a partir del poder de representación que poseen ambos medios, el rastro que se va depositando en la obra atiende a una doble referencialidad que implica una memoria que remite al motivo real del que parte, por un lado, y a lo concerniente al propio medio que actúa como paradigma, en el caso de la pintura, por otro.

Comenzar, por tanto, apuntando a la tecnología inherente que cada medio desarrolla, nos lleva a hablar de una forma de mirar distintiva de cada uno de ellos, y a un debate que aún hoy continúa, en el sentido de determinar qué es lo pictórico y qué lo fotográfico, como cualidades propias e intransferibles que los delimitarían. Una diferenciación que, aunque en los inicios de la fotografía se muestra de manera intensificada, se va atenuando al hacerse más destacable la parte procesual de la construcción de la imagen:

Con frecuencia se confunden las actividades genéricas (términos en minúscula: pintura, fotografía, arte) con los paradigmas artísticos (términos en mayúsculas: Pintura, Fotografía, Arte). Mientras la fotografía y la pintura cuando se habla de ellas como actividades genéricas, se distinguen clara y meramente a partir de su tecnología - pinceles vs. cámaras-, cuando se las trata como paradigmas sin embargo, la diferencia no es tan explícita: ésta se intenta establecer a través de propiedades inherentes o cualidades esenciales que quedan siempre indefinidas. Se confunde un género con una de sus muchas posibilidades expresivas (González Flores, 2005, p. 296). 
Aunque sirva de referencia para muchos discursos plásticos, en muchas ocasiones la técnica pasa a un segundo plano para poner el énfasis en el mensaje que pretende transmitir la imagen, en estrecha correlación con los valores culturales subyacentes en la misma. Lo que verdaderamente, en última instancia, puede llegar a definir si una obra es fotográfica o pictórica, independientemente del medio expresivo del que partan, reside en la determinada postura reflexiva o filosófica a la que nos haya conducido cierto discurso crítico e ideológico.

Mientras el pictorialismo como movimiento entra en decadencia, aparecen otros artistas que, desde otras vertientes estilísticas, tratan de defender la fotografía como arte. Tal es el caso de Lásló Moholy-Nagy (2005, p. 148), quien trata de esclarecer las relaciones entre pintura y fotografía en Pintura, Fotografía, Cine (1925), donde acuña el concepto de "fotoplástica" como "manera de transformar el procedimiento fotográfico imitativo en una actividad artística programática”. Man Ray, por su parte, en 1922 se decanta por la experimentación en el laboratorio alumbrando la técnica del rayograma, en la cual se aprovecha la sensibilidad a la luz del papel fotográfico para, intersectando objetos traslúcidos y transparentes entre la fuente de iluminación y el soporte, crear espectrales composiciones. Un procedimiento por el que lo único que se conserva de la fotografía es aquello que soporta la imagen final, lo cual rompe con la creencia de la existencia de cierta lógica interna de la técnica fotográfica que llevaba a sus ejecutantes a pensar que no podía haber fotografía sin cámara. Dada su plasticidad, supone un método icónico que posee mucha relación con la pintura. Desde este tipo de experiencias, y dejando atrás ya el movimiento pictorialista, el guiño a lo pictórico supone una tónica aún hoy practicada desde la fotografía.

A pesar de que este tema aún hoy siga siendo controvertido, sin embargo abre un fructífero campo para aquellas manifestaciones artísticas que ahora pretenden moverse entre apariencias para generar su discurso; límites borrosos desde los cuales a veces no se identifica ya muy bien el medio específico del que parten, pero que posibilitan la multiplicación de correspondencias entre las artes. Esta nueva forma de experimentar, entre la 
prueba y el error plástico, permite que muchos artistas puedan referir desde la fotografía a la pintura o viceversa. Desde esa libertad expresiva que va más allá de los condicionamientos propios de cada disciplina, puede que las finalidades de ambos medios no sean tan diferentes, sino que, en aras del ensayo creativo, traten de revelar otros mundos. Por eso mismo, las relaciones que llevan al diálogo entre pintura y fotografía, serán objeto de análisis por parte de muchos pensadores. Tal es el caso de Otto Stelzer o Aaron Scharf, quienes observan cómo las muchas potencialidades de la fotografía suponen un estímulo para el origen de nuevos estilos pictóricos, repasando distintas concepciones fotográficas y comprobando cómo implican una significativa influencia. Respecto a ello:

La historia de la pintura en la era de la fotografía está determinada en muchos aspectos por el encuentro entre dos medios que se buscaban mutuamente, pero que también se rehuían. (...) A la pintura sólo le quedaba la elección entre mantenerse firme o huir. Podía aceptar la visión fotográfica e intentar desarrollar más la capacidad del objetivo con el cual trabajaba, es decir, del ojo humano: el impresionismo, un naturalismo de lo subjetivo, fue en principio un método coincidente con el proceso fotográfico. La construcción del cuadro a partir de partículas de color se correspondía al grano de la fotografía; el resultado era una reproducción en color de la realidad, tal como no le era posible captarla a la cámara. O bien - y ésta era la segunda posibilidad - la pintura se retiraba hacia unas posiciones a las que no pudiera seguirle la fotografía; uno de estos refugios era la abstracción. (Stelzer, 1981, pp. 173174）

Como señala Stelzer, cada medio, en la búsqueda de lo propio de sí mismo, emprende una aventura experimental repleta de inevitables intersecciones. De ahí que, superados los primeros prejuicios que constriñen a ambos dentro de unas pautas encorsetadas en pro de la defensa disciplinar, sea conveniente indicar cómo los procesos expresivos de dos medios que se cuestionan mutuamente, desde una "transparente delimitación", facilitan traducciones diversas derivadas de una "inter-expresión" que no busca necesariamente justificaciones excesivamente razonadas para tales manifestaciones plásticas, sino dar lugar a cierta "lógica de la sensación". Pues, desde una perspectiva 
fenomenológica, lo que se acaba "fijando" desde uno u otro medio -o su hibridación- "es el cuerpo, no en tanto que se representa como objeto, sino que es vivido como experimentando tal sensación” (Bacon, 2005, p. 42). Desde la libertad subjetiva que otorga dejarse guiar por la sensación, las intersecciones mediáticas se intensifican con la posmodernidad, lo cual a su vez provoca una tendencia hacia una disolución disciplinar -en tanto que límites y categorías constitutivas del mismo proyecto moderno- que puede decantarse en un cierto sinsentido desde el cual el propio arte, como categoría ontológica, es puesto en cuestión (Crimp, 2001, p. 176).

Intersecciones pictóricas desde la fotografía como, por ejemplo, representan los trabajos de artistas contemporáneos como Wolfgang Tillmans, quien no utiliza cámara ni negativos para la realización de sus desleídas composiciones abstractas, trabajando de manera directa sobre el papel fotosensible a través de diversas manipulaciones que implican el manejo azaroso del color, la luz y los diferentes accidentes como "la adición de pliegues o arrugas que abren las fotografías al espacio tridimensional” (Werner Holzwarth, 2008, p. 456). Este tipo de intervenciones animan a abordar la situación desde la perspectiva del híbrido fotografía-pintura o pintura-fotografía. Se podría hablar entonces de un territorio intersticial como desde el que trabaja Darío Urzay, quien acude al medio fotográfico en busca de una ampliación de la gramática pictórica. En esa línea, su serie Camerastrokes (1994) sustituye sus habituales brochas de pintor por una cámara fotográfica que "gestualiza" el trazo, obteniendo fotografías ante fuentes lumínicas como si estuviera dando pinceladas. La sencillez de este primer estadio, se va complicando a medida que Urzay permite que la pintura "se pinte" dentro del mismo proceso, registrando accidentes físico-químicos de la propia pintura que acaba incorporando a la composición. Seguidamente, pasa al reprocesado de estas impresiones mediante el tratamiento infográfico (Jaukkuri, 2004, p. 140). El resultado estético de estas intrincadas transformaciones, son abstractas composiciones orgánicas que mantienen una estrecha relación con el aspecto que presentan los cultivos biológicos vistos al microscopio o, desde una macroescala, con la fluidez cósmica de un universo en suspensión. 


\section{La alusión a la memoria de las imágenes borrosas en fotografía y pintura}

A través de la manipulación del objetivo de la cámara fotográfica es fácil obtener imágenes borrosas, pero aunque parezca un procedimiento propio de la fotografía este ya se realiza con anterioridad en pintura con intención de velar, borrar, disimular u ocultar, en ocasiones, y para ofrecer cierta sensación de movimiento en otras. Grosso modo, la pintura se compone de "borrones" de color que, discriminándose o integrándose, van confeccionando formas en las cuales, a partir de las dinámicas vectoriales que adquieren las masas de color, apreciamos pinceladas más o menos arrastradas o difuminadas. Este juego lleva al pintor a una perpetua negociación entre la aparición y el borrado, de lo cual se puede conservar algún indicio a modo de pentimenti o arrepentimiento atisbado ligeramente. Más que ocultar, que supone esconder algo detrás de otra cosa, la pintura que se muestra borrosa, o ciertamente velada, disuelve las formas para situarlas entre una frágil presencia y su indefinida desaparición; una visibilidad de pérdidas progresivamente imperceptibles.

Leonardo Da Vinci, quien describe la pintura como cosa mentale, desarrolla el sfumato como un método para obtener contornos imprecisos en las formas, a través de la cuidadosa superposición de capas de veladuras que confieren una sensación de profundidad y lejanía a la imagen. En este tipo de imágenes se puede apreciar cómo las formas más alejadas del primer plano se van disolviendo progresivamente. Esta suma de contornos desdibujados que propone Da Vinci, será un procedimiento seguido por otros artistas como Rembrandt o William Turner. De este último, por ejemplo, es destacable cómo experimenta hasta el paroxismo con la materia pictórica para reflejar, a través de la indefinición, una realidad que comienza a acelerarse a causa de la Revolución Industrial del Siglo XIX. Heredero de una tradición que evoluciona desde el Renacimiento, Turner abre la puerta al impresionismo pues:

La pintura barroca abre la visión con límites desdibujados, focos tenues y múltiples perspectivas, ofreciendo una invitación clara y táctil y tentando al 
cuerpo a viajar por el espacio ilusorio. (...) los cuadros de J. M. William Turner prosiguen con la eliminación del encuadre de la imagen y la posición estratégica que arrancó en la época barroca; los impresionistas abandonan la línea fronteriza, el encuadre equilibrado y la profundidad de la perspectiva; Paul Cézanne aspira a hacer visible cómo nos toca el mundo. (Pallasma, 2006, p. 34).

Este desenfoque de la imagen parece la forma de crear una especie de membrana aterciopelada desde la cual el espectador puede acceder a la representación de la realidad, tocar su piel; "zonas borrosas que representan los espacios periféricos por explorar" (Alcalá, 2011, p. 28). Así, un desleimiento de las formas caracteriza el impresionismo transformando su tematización con la introducción de nuevos motivos que, en ocasiones, tienen relación con las revoluciones técnicas del momento. Este modo de acercarse a la representación del mundo lleva implícita la simplificación compositiva y la ruptura con los modelos académicos tradicionales, anunciando la llegada de las vanguardias artísticas del siglo XX. Ejemplo claro de ese ambiente disipado en el que parece desaparecer el motivo es, por ejemplo, la representación de cortinas de humo que, ocupando gran parte del encuadre, envuelven algunos elementos tras una atmosférica nebulosa proveniente de las máquinas de vapor, por ejemplo. A este respecto:

Podríamos concluir afirmando que en este caso -al contrario de lo que ocurría en la tradición- la dificultad de la mirada adquiere un matiz poético gracias al intercambio de papeles que implícitamente corresponderían al espectador: su ¿derecho a ver claro? Se difumina (Stoichita, 2005, p. 31).

A partir de entonces lo tecnológico parece instaurarse como modelo de referencia técnico o temático que, igualmente, lleva a muchos pintores a considerar los resultados estéticos obtenidos mediante la propia mecánica de los procesos fotográficos. En ese sentido, quizá el artista contemporáneo que más intensamente ha remitido a lo fotográfico sea Gerhard Richter. Dejando en suspenso la eterna dialéctica entre pintura e imagen fotográfica, los cuadros que este dedica a la borrosidad parecen intentos por comprender la confusión que entraña la contemporaneidad. 
En esta confrontación, sin embargo, prevalece la imagen fotográfica sobre la pintura, pues su objetivo no es copiar fotografías ni pintar telas que perezcan fotografías, "sino crear fotografías a través de medios plásticos" (Lebeer, 1997, pp. 242-243). Esta correspondencia entre ambas formas de obtención de imágenes que llega, como en el caso citado, a la suplantación, nos insta a pensar en lo contrario: que muchas obras creadas desde el medio fotográfico pueden ser pinturas. Desde esta perspectiva, la adscripción de una obra a uno u otro medio dependerá más de una discusión filtrada por la filosofía de la imagen, que articula la semiótica con el enfoque perceptualista -en atención a la captación de lo sensible-, que de una constricción ceñida a cuestiones específicamente técnicas o materiales.

En ese tipo de cuadros la borrosidad impone un velo sobre la imagen que impulsa a la reflexión sobre los conceptos de presencia y ausencia. Por ello, si bien en Richter la borrosidad pictórica recuerda a la que produce una lente fotográfica desenfocada, todo procedimiento de este tipo acaba haciendo alusión a la espectralidad, como supuesto tránsito entre la vida y la muerte. En ese sentido, el spectrum de la fotografía, así denominado por Roland Barthes (1990, p. 35), "mantiene a través de su raíz etimológica una relación con 'espectáculo' y le añade ese algo que hay en toda fotografía: el retorno de lo muerto”. Desde esa cláusula, la pintura evidencia dicho carácter tanático a través del guiño que hace al medio fotográfico. Una relación entre lo pasado y ausente de la historia personal o general que lleva al recuerdo de aquello que ha desaparecido. Desde esta correspondencia con la memoria, la levedad gestual implícita en las imágenes desenfocadas desarrolla toda una filosofía de lo sutil, lo tenue, lo efímero o lo evanescente donde el motivo y sus detalles pasan desapercibidos para enfatizar esa dimensión mnemónica.

Este efecto flou, desde el paradigma fotográfico al que tienden algunas pinturas contemporáneas, indica la existencia de una condición humana que dialoga a un nivel temporal que, pudiendo en ocasiones hacer referencia al movimiento y la acción, siempre implica memoria y velocidad. Esta huella de carácter mecánico que añade detalles que, en principio, pueden pasar desapercibidos, hace alusión al "inconsciente óptico" apuntado por Walter 
Benjamin (1989, p. 67). A partir de este concepto, Rosalind Krauss (1997, p. 39) propone explicar la racionalidad óptica del arte moderno a partir de la desestabilización entre figura y fondo, la cual conlleva una oposición compleja y radical entre la visión perceptiva y la reflexiva que emborrona su nítido enfoque, resituando lo visual en una opaca autonomía que se halla condicionada por automatismos inconscientes: "el inconsciente óptico reivindicará para sí esta dimensión opaca, repetitiva, temporal. Se desplegará sobre la lógica modernista sólo para atravesar su núcleo, para deshacerlo, para reconfigurarla de otra manera”.

Tomando en cuenta estas referencias ineludibles, José Luis Brea establece que:

el sentido de esta transformación 'psicológica' del modo de darse la experiencia artística (...) se resuelve entonces en los términos positivos de una secularización de la experiencia, que progresivamente habrá de acabar por transformarse en mera experiencia de conocimiento (1996, p. 31).

Extendiendo esta afirmación al hecho de que aquello que se ve contiene una epísteme implícita, puede existir una equiparación entre el ver y el saber donde la imagen borrosa, en su pérdida de detalle, acarrea un problema de análisis. Según este estado confusión: "hay algo en lo que vemos que no sabemos que vemos, o algo que conocemos en los que vemos que no sabemos 'suficientemente' que conocemos". Una situación que pudiéndose corresponder, tras la explosión de las tecnologías de la información y la comunicación, a una metáfora del momento presente supone una "estructura abstracta que determina el campo de lo cognoscible en el campo de lo visible" (Brea, 2007, p. 146).

Esta forma de vinculación de la imagen fotográfica a cuestiones del individuo contemporáneo es aprovechada en gran medida por la pintura, que mediante esa referencia alude a un tipo concreto de experimentación simbólica de la imagen y la memoria que genera. Además de Richter, se pueden citar, entre otros, pintores como Johannes Kahrs o Henrik Löning, quienes siguen la estela de este perpetuo cuestionamiento de la perdurabilidad de la imagen, y 
el transitar por la memoria colectiva, mediante su borrosa presencia, lo que también podría insinuar cierta pérdida de identidad psicológica del individuo frente a la colectividad. Procedimientos de destrucción o barrido de lo representado que, aun no siendo nuevos, remiten ahora inmediatamente a lo fotográfico aportando un realismo e ilusionismo mayor a la imagen. En ese sentido, ya Leonardo Da Vinci (1986, p. 366) aconsejaba difuminar con suavidad los contornos de las figuras para conseguir mayor realismo. Una disolución de las formas de la que se vale también Velázquez, y, en atención a este, desarrolla Manet abriendo paso al Impresionismo.

A partir de ese momento, tal como demuestran los pintores contemporáneos citados, la referencialidad a la fotografía es doble y conlleva atender a procesos de la memoria que, relacionando espacios y tiempos, ubican al espectador en una perspectiva materialista de la historia; una ante-historia de lo que realmente interesa que lo aleja de la apariencia de repetición. Por tanto, a partir de esa remisión a lo fotográfico los momentos de la historia importan porque "se convierten en momentos del presente a través de su índice en tanto 'ante-historia', y cambian sus características de acuerdo con la determinación catastrófica o triunfante de aquel presente” (Crary, 2008, p. 14). Así es como la capacidad de transmisión de realidad y su significado se equiparan, pues lo que se ve en estas imágenes: "no parece ser símbolos que necesiten ser descifrados, sino síntomas del mundo, a través de los cuales se reconoce, aunque indirectamente, el mundo" (Flusser, 2001, p. 18).

Ejemplo de esta memoria histórica que se desvanece, es el trabajo de Luc Tuymans, para quien las fotografías utilizadas en los medios de comunicación representan un documento de referencia imprescindible. Heredero de una sólida formación flamenca de corte figurativa, su técnica es de una parca policromía y de contrastes que se vuelven imperceptibles en ocasiones. Por otro lado, cercano a este, pero sin tanta carga histórica, se halla la pintura de Michaël Borremans, más preocupado en reflejar una intrahistoria personal misteriosa y extremadamente melancólica que se acerca, en algunas obras, a cierto delirio surrealista. Momentos, en muchas ocasiones escenográficos, que se acercan a los que también desarrolla 
Phillipp Fröhlich, quien, partiendo de maquetas, realiza fotografías que traslada a la pintura mediante un código mecánico y repetitivo que disuelve la imagen en su conjunto.

\section{La mirada del espectador ante la fugacidad de las imágenes desenfocadas}

Hablar de memoria y de la construcción histórica de la visión es aludir, igualmente, a los regímenes escópicos que conforman la percepción y la epistemología de la Modernidad. Según Martin Jay (2003), los tres regímenes escópicos son: el perspectivismo cartesiano, donde la visión se ordena a partir de la visión del sujeto; el empírico, preocupado por la descripción y la introducción del espectador dentro del campo de la representación; y el barroco, que multiplica espacios visuales y niveles de comprensión de la imagen. Según este autor, durante el siglo XX se vive "un singular reto contra el orden jerárquico de los tres regímenes” (Ibib., p. 237). Referir a la mirada que despliega el espectador ante las imágenes aquí tratadas, supone, como denomina Miguel Ángel Hernández-Navarro (2007, p. 28), configurar una “cartografía de la visión” desde la sospecha de que este "archivo escópico de la Modernidad -la condición de posibilidad de lo visible- está constituido por una crisis de verdad de lo visible: la toma de conciencia de que hay cosas que no podemos ver, y que las cosas que vemos no son de fiar”. Esta situación ocasiona "un punto ciego de la visión, algo que no puede ser visto del todo, un lado oscuro, una falta, un objeto inasumible, inapreciable, inhaprensible”.

Brea (2007, p. 148) comenta al respecto que "el ver no es neutro" sino un acto “complejo y cultural y políticamente construido". Por ello, puede que ante la hipersaturación icónica actual, la lógica de la mirada del espectador ya no se asiente en los regímenes escópicos establecidos por el arte, como campo que investiga los "umbrales de lo visible", ni sobre la idea de que existe un inconsciente óptico, un "punto ciego", que solo la cámara fotográfica puede captar, o de que en los actos de ver (artísticos) existe una "articulación que tiene como nota distintiva la importancia en su estructura 
de campo de una cierta zona de punto ciego, o de "inconsciente óptico” (p. 150).

Este nuevo régimen escópico contemporáneo por el que, como "singular reto" se pregunta Jay y Brea resuelve en la e-image, viene instaurado a causa de la hipersaturación icónica que acarrea lo digital, cuya epísteme escópica posiblemente ya "no se ordena más alrededor del supuesto de un punto ciego en su seno, sino bajo una lógica definitivamente distinta” que establece la $e$ image como "preconfiguración del puro fantasma", que puede que ya fuera convocado con las con las imágenes borrosas pictórico-fotográficas, o con la velocidad que trata de atrapar la cronofotografía que sirve de inspiración a la pintura. En ese sentido, dentro de los parámetros actuales el ordenador, como dispositivo, actúa como “"un segundo obturador' que no congela el tiempo sino que lo convierte en un 'tiempo-movimiento', en un 'instantedevenir' implícito que se despliega en el tiempo expandido de la lectura de la imagen" (Mira, 2015, p.73).

Al igual que la imagen digital, las imágenes borrosas o las cronofotografías nos hablan de contingencia y fugacidad siendo, a su vez, la misma memoria a la que antes se aludía, abolida de algún modo. En ese tipo de "imagentiempo" transitoria, directamente relacionada con el cine, no se halla el presente ni tampoco el recuerdo. Se percibe, en cambio, un orden temporal donde los signos de tiempo son inseparables de signos de pensamiento y de palabra (Deleuze, 1987), causando una fractura tanto en la sucesión empírica como en la memoria psicológica. Ante la crisis de una "verdad" confiada al ocularcentrismo expandido, o "insuficiencia de la visión como herramienta de conocimiento" (Hernández-Navarro, 2007, p. 33), nace un nuevo estatus de la imagen que, abriendo un compendio de condiciones de posibilidad, repercute en la visualidad y los valores que el conjunto de la sociedad otorga a esta, pues "nunca miramos sólo una cosa; siempre miramos la relación entre las cosas y nosotros mismos" (Berger, 2016, p.9).

La fugacidad inserta en las imágenes desenfocadas, como "estética de la desaparición" que la "sombra del tiempo" (Virilio, 1988, p. 18) de la pintura refleja al representar la "luz fotográfica" de referencia, llevan al espectador a 
bifurcar su recepción entre una visión óptica y un acercamiento plástico de carácter táctil. De ahí que su visibilidad real se halla en "la condición de posibilidad de lo visible, la razón de las cosas (de las imágenes) y de los modos de verlas (de aprehenderlas)” (Hernández-Navarro, 2007, p. 76), que siempre se hallará sujeta a las relaciones de poder del "afuera" -que desde la dominación imponen la "verdad” y el saber de cada momento-, pero también de un "adentro impensado" establecido por la subjetividad de cada individuo. Desde esta dicotomía, parece que en la "carrera" de la epísteme escópica el aparato técnico que representa la fotografía toma la delantera al ojo ante la “ceguera de lo visible” (Ibid., 2007, p. 97), como fenómeno que el espectador experimenta en la actualidad, porque "la memoria fotográfica, a diferencia de la humana, nunca olvida y trae el pasado al presente cada vez que se mira” (Ibid.).

Una "verdad" y un saber ante el descubrimiento de determinados puntos ciegos que habían pasado desapercibidos, que es puesta en entredicho y "revelados" por una fotografía que, sin embargo, también puede estar sujeta a tanta manipulación como la pintura. Por esa razón, lo que en principio se llega a establecer como un medio de conocimiento que desbanca al ojo, puede tornar ahora en "profunda crisis en el campo de la visión” (Ibid., p. 99) que desemboca en "una desconfianza y recelo ante lo visible, no sólo por no poder conocerlo, sino por temer ser objeto de engaño". En este estado el espectador, así como la imagen borrosa dilata el tiempo desde una desaparición perpetua que impide que la mirada penetre analíticamente, pone en suspenso cualquier certidumbre de conocimiento desde este atrofiado ver.

Este régimen de desconfianza es al que Hernández-Navarro denomina como "escotómico" (Ibid., p. 112), "ya que es la puesta en evidencia de esta ausencia, imposible de llenar, la que preside su epistemología” (Ibid.), como definitivo "punto ciego" que funciona a modo de obstrucción para el ojo: "no permite ver del todo, un escotoma que oculta algo a la visión, se erige en nuevo paradigma del saber" (Ibid.). Es desde este "régimen de sombra", que inaugura la sospecha de lo visible, el que puede deparar en alternativos y 
resistentes modelos de visibilidad que continuamente tratan de evidenciar el punto ciego de la mirada que, finalmente, no es otra cosa que "la constatación de la intraducibilidad de lo visible" (Ibid., p. 130), pues: "hay más en lo que vemos, y, en lo que vemos, no está todo lo que hay" (Ibid, p. 122). Lo cual supone abogar por una "mirada defensiva", como denomina Juhani Pallasmaa (2006, p. 13), "y desenfocada de nuestro tiempo, sobrecargada sensorialmente", que "puede abrir nuevos campos de visión y pensamientos liberados del deseo implícito del control y poder del ojo. La pérdida de foco puede liberar al ojo del dominio patriarcal histórico”.

\section{Referencialidad fotográfica y dimensión cinemática en pintura}

Como se ha establecido, a través de la remisión que realiza la pintura a la imagen borrosa proveniente de la fotografía, se puede aludir al concepto de imagen-tiempo que desarrolla Deleuze, reuniendo signos de tiempo, memoria, pensamiento y palabra en una dimensión tendente a lo narrativo. Pero también hay determinada pintura que, tomando también como referencia a la fotografía, puede hacer alusión a la noción de "imagenmovimiento" igualmente tratada por Deleuze (1984) en referencia al cine. Sin embargo, persiguiendo constatar cierta sensación de movimiento que la pintura basada en la imagen borrosa y en las cronofotografías puede llegar a transmitir -lo cual supone aludir a algo que no se halla en la imagen fija sino en aquello que puede interpretar el espectador-, quizá lo aquí propuesto se acerque más a las premisas expuestas por Henri Berson, quien considera que, antes del cine, ya existe una "ilusión cinematográfica” en el propio mecanismo de la percepción y del pensamiento. Dicha ilusión, puede trasladar al espectador, desde los casos pictóricos aquí contemplados, a cierta dimensión cinemática aun desde su imagen fija, dado que "cada uno de nuestros actos apunta hacia una cierta inserción de nuestra voluntad cinematográfica- en la realidad” (Bergson, 1963, p. 701), en este caso pictórica.

La cinemática, como rama de la física que describe el movimiento de los objetos sólidos sin considerar las causas que los originan -limitándose al 
estudio de la trayectoria en función del tiempo-, se convoca aquí por su participación alegórica al tema tratado. La narratividad que puede existir en la imagen borrosa de la pintura a partir de la fotografía, tiene mucha relación con la experiencia perceptiva y un tiempo fenomenológico implícito, como "fuerza constativa" de la fotografía que atañe al mismo tiempo, no al objeto (Barthes, 1990, p. 155). En ese sentido, tanto en la pintura como en la fotografía siempre se registra una continuidad espacio-temporal de modo tan diferenciado que se ha de acudir a cuestiones semióticas, anteriormente aludidas, para comprobar cómo se pueden llegar a acceder esa sensación cinemática que se intuye, a partir del análisis del "puro 'significante' en su sustancia dotada de una forma diferencial respecto de otras formas posibles" (Peirce, 1987, p. 13-14).

Según Dubois (2010, p. 20) lo específico del acto fotográfico se establece a partir de su correspondencia con el referente pudiendo aparecer como “espejo de lo real”, a modo de mímesis transparente y objetiva; transformación de lo real, en cuanto a su parte de construcción subjetiva; y como "huella de un real" (Ibid., p. 21), a modo de efecto que nos permite deducir la existencia de algo real, pues existe una relación de proximidad entre el signo y su referente. La constitución de este index que conecta signo y referente, se extiende también por la pintura que toma como referencia a la fotografía por partida doble: el signo pictórico refiere a la existencia real de la fotografía, como el signo fotográfico que imita remite a la existencia de una realidad.

Pero, más allá del significante como huella de una realidad, tratar de discernir aquí esa sensación de movimiento a la que puede remitirnos una imagen pictórica cuyo referente es la fotografía, es acercar el concepto de punctum, como significado personal y subjetivo que cada espectador puede otorgar, al de studium, como valoraciones universales; "campo tan vasto del deseo indolente, del interés diverso, del gusto inconsecuente" (Barthes, 1990, p. 11). Porque, desde la condición de un espectador cuya percepción se halla cada vez más suspendida entre un espacio de lo visual que ha entrado en crisis, sentir que algo -un detalle- atrae su mirada y le hace cambiar su 
lectura otorgando un valor superior, es sinónimo de que este punctum le ha punzado (Ibid., p. 87). Aun así, como avisa Barthes, "no es posible establecer una regla de enlace entre el studium y el punctum”, sino que este último será una especie de "copresencia” añadida, tal y como corresponde a la dimensión cinemática que ahora se pretende adjuntar a determinadas pinturas construidas a partir de la referencia a fotografías borrosas y cronofotografías.

El tiempo como duración de la acción es algo que interesa a esa parte de la fotografía que estudia el movimiento, como en el caso de las empíricas cronofotografías de Etienne Jules Marey, que realiza mediante una "escopeta fotográfica”, y de Eadweard Muybridge. Imágenes que, como inspiración, aprovecha cierta pintura a fin de sintetizar dicho fenómeno a través de la gestualidad que puede darse mediante la expresión plástica. Pues verse visualmente "limitado" ante el aparato fotográfico, en tanto que delator del "punto ciego" anteriormente aludido, incita "a la búsqueda de nuevos horizontes perceptivos y a la posibilidad de nuevas articulaciones entre lo real y sus posibles derivaciones estéticas” (Mah, 2010, p. 15).

Desde las inquietudes de los propios creadores, quienes interpretan y traducen este tipo de fotografía a partir de un punctum personal, también existe, según asegura Mary Ann Doane (2002, p.6), “el deseo de analizar y racionalizar el tiempo" que, con frecuencia, se halla "detrás del deseo de hacer el tiempo visible”. Esta transmisión de lo temporal desde la imagen borrosa se ha comprobado que acaba en inducir, finalmente, a cierta dimensión atemporal, pues el pasado parece disolverse en la constancia de una imagen que se halla en perpetua desaparición. Igualmente, esta continua transición entre presencia y ausencia acaba por informar de cierto movimiento inmanente o durativo, que puede llevar a una especulación sobre el carácter cinemático de determinadas representaciones pictóricas. Pero, por otro lado, tomar como referencia la cronofotografía es aludir al movimiento y a un tiempo acotado que, al contrario que en el caso anterior, no se expande, sino que sucede puntualmente entre dos momentos.

En este sentido, la representación del movimiento por parte de la pintura es una constante que se repite a lo largo de toda su historia. Desde la 
recurrencia a imágenes diacrónicas en el Renacimiento, donde secuencias consecutivas son realizadas en un mismo plano de representación, hasta, por el contrario, hacer desaparecer determinados elementos de la representación para transmitir dicha sensación, como sucede en el cuadro Las hilanderas (1657), de Velázquez, quien desdibuja los radios de la rueca para denotar su dinamismo. Recurso que, igualmente, fue seguido por la pintura impresionista, siendo en realidad el futurismo, y el método del "simultaneismo" consistente en superponer imágenes -de un modo parecido a cómo lo hicieron Marey y Muybridge- para mostrar esquemáticamente diferentes fases del proceso dinámico del motivo en una misma representación, la corriente que más incidió en la búsqueda de esta transcripción.

Con un procedimiento similar al descrito, pero más cercano al movimiento cubista, Marcel Duchamp y su obra Desnudo bajando la escalera (1912) supone un buen ejemplo de esta técnica de superposición. Respecto a esta, es significativo destacar que pintó dos versiones que, expuestas juntas, servían para analizar ciertas cuestiones de la imagen estroboscópica. Igualmente, esta dimensión cinemática de la pintura a partir de la referencia que facilita la cronofotografía es excepcionalmente transmitida por Francis Bacon, quien se inspira en el libro de Muybridge titulado: The Human Figure in Motion (1907) para componer algunos de sus cuadros.

Para este pintor la fotografía es un objeto que le distancia del hecho real para hacerle volver más violentamente a este, pues, como él mismo expresa: “a través de la imagen fotográfica comienzo de pronto a vagar dentro de la imagen y abro lo que yo considero su realidad más de lo que podría hacerlo mirando directamente. Las fotografías no son sólo puntos de referencia. Son muy a menudo reactivadoras de ideas." (Sylvester, 2009, p. 31). Para explicar cómo concibe el movimiento, hemos de recurrir a la "hipótesis motriz" que, diferenciada de la "hipótesis fenomenológica", afectando también a la dimensión corporal, Deleuze (2005, p. 48) reflexiona en Lógica de la sensación (1981), siendo, en último término, "un movimiento sin moverse del 
sitio, un espasmo, que testimonia un problema propio de Bacon: la acción sobre el cuerpo de fuerzas invisibles".

\section{Conclusiones}

Partir del punto ciego como metáfora de una visión complementaria que puede existir entre los (des)enfoques que plantean la fotografía y la pintura, cuando esta última toma las imágenes borrosas y la cronofotografía de la primera como referente, supone desplegar un juego cruzado donde la información visual que aporta la primera se sobredimensiona a través de la plasticidad de la segunda. A su vez, entre lo eminentemente óptico y lo táctil evoluciona, inevitablemente, una crisis escópica producto de la instauración de la imagen digital, la cual trastoca la huella de lo real, o index, tergiversando, igualmente, el acto fotográfico y la remisión que a este realiza la pintura.

Por una parte, la referencia al inconsciente óptico al que se refiere Benjamin, desarrolla Krauss en profundidad, y vuelven a recordar Brea o HernándezNavarro, es ineludible. Ello hace que el espectador comprenda que el mecanismo fotográfico puede captar detalles que al ojo le pasan desapercibidos, pero también que siempre existe algo más allá en la imagen que no vemos y da pie al desarrollo de estudios comparativos como el presente. Por eso mismo, la sospecha de que siempre existe algo más escondido e intraducible en lo visible, como "punto ciego" de la epísteme escópica, conduce a seguir indagando sobre las diversas correspondencias que se encuentran entre cada medio icónico tratado. Por esta razón, ante el "régimen de luz" que supone la constatación empírica a la que podía llevar la imagen fotográfica, ahora, sabiendo las múltiples manipulaciones a la que puede exponerse, es lógico que, desde una fundada desconfianza, tanto artistas como espectadores se muevan dentro de un "régimen de sombra" que abre el campo de las posibilidades experimentales para los primeros y de la curiosa posible salida de cierta suspensión perceptiva para los segundos. 
Al convocar memoria y tiempo desde un tipo de imagen que está perpetuamente desapareciendo, tanto la fotografía borrosa como la pintura que la imita, poseen un carácter fugaz que, por compartir esta misma cualidad, ya anuncian el nuevo estatus que establece la imagen digital actual. Esa dimensión cinemática que ahí se inserta, la cual corresponde más a la voluntad del que mira que a la propia imagen estática, es enfatizada por aquel tipo de pintura que toma las cronofotografías como inspiración para su construcción plástica. En cambio, si con las imágenes borrosas el tiempo parecía expandirse, con estas últimas se alude a un lapsus cinético que, condensado, alude a cierta sacudida corporal o espasmo fenomenológico.

Aunque sinceramente se haya expuesto la crisis por la que, algunos autores consideran, atraviesa lo visual, delatar aún la existencia de "puntos ciegos" en la propia conformación de lo visual, tomando como punto de partida la relación mediática del presente caso, potencializa la investigación y la praxis creativa. Al final de este sintético recorrido, por tanto, lo que se podía considerar como una iniciación de lo "anti-retiniano", por esa atrofia del ver al que transportan las imágenes tratadas, se convierte en toda una zona borrosa que, efectivamente, extendiendo la competencia de cada disciplina conduce a la comprensión de la propia borrosidad -su tiempo, memoria y movimiento implícitos-, como una metáfora del momento actual, la cual abre nuevas opciones a la configuración visual de la epísteme. Opciones que, para que se puedan dar, necesariamente han de volverse resistentes para escapar de las icónicas relaciones de poder hegemónicamente establecidas.

\section{Referencias bibliográficas}

Adorno, T. W. (2008). El arte y las artes. En Crítica de la cultura y sociedad I. Prismas. Sin imagen directriz. Madrid: Akal.

Alcalá, J. R. (2001). La piel de la imagen. Ensayos sobre la gráfica en la cultura digital. Valencia: Sendemá.

Barthes, R. (1990). La cámara lúcida. Nota sobre la fotografía. Barcelona: Paidós. 
Benjamin, W. (1989). Pequeña historia de la fotografía. En Walter Benjamin: Discursos interrumpido I: Filosofía del arte y de la historia. Buenos Aires: Taurus, pp. 61-83.

Berger, J. (2016). Modos de ver. Barcelona: Gustavo Gili.

Bergson, H. (1963). Obras escogidas. Madrid: Aguilar

Brea, J. L. (1996). El inconsciente óptico y el segundo obturador: la fotografía en la era de su computerización. En José Luis Brea: Un ruido secreto: El arte en la era póstuma de la cultura. Murcia: Mestizo.

Brea, J. L. (2007). Cambio de régimen escópico: del inconsciente óptico a la e-image. En Estudio visuales: Ensayo, teoría y crítica de la cultura visual y el arte contemporáneo, $\mathrm{n}^{\mathrm{O}} 4$ ¿Un diferendo “arte”?, pp.145163.

Crary, J. (2008). Las técnicas del observador. Visión y modernidad en el siglo XIX. Murcia: Cendeac.

Crimp, D. (2001). Imágenes. En Wallis, Brian (ed.), Arte después de la modernidad. Nuevos planteamientos en torno a la representación. Madrid: Akal.

Da Vinci, L. (1986). Tratado de Pintura, Madrid: Akal.

Deleuze, G. (2005). Francis Bacon. Lógica de la sensación. Madrid: Arena Libros.

Deleuze, G. (1987). La imagen-tiempo. Estudios sobre cine 2. Barcelona: Paidós.

Deleuze, G. (1984). La imagen-movimiento. Estudios sobre el cine 1. Barcelona: Paidós.

Doane, M. A. (2002). The Emergence of Cinematic Time. Modernity, Contingency, The Archive. Cambridge: Harvard University Press.

Dubois, P. (2010). El acto fotográfico. Madrid: Paidós.

Flusser, V. (2001). Una filosofía de la fotografía. Madrid: Síntesis.

Fontcuberta, J. (2003). Estética de la fotografía. Barcelona: Gustavo Gili.

Hernández Navarro, M. Á. (2007). El archivo escotómico de la modernodad (pequeños pasos para una cartografía de la visión). Alcobendas: Ayuntamiento de Alcobendas.

Jaukkuri, M. (2004). Fluyendo dispersando. En catálogo de exposición: Darío Urzay. En una fracción. Madrid: Distrito 4, p. 140.

Jay, M. (2003). Regímenes escópicos de la modernidad. En Campos de fuerza. Entre la historia intelectual y la crítica cultural. Buenos Aires: Paidós.

Krauss, R. E. (1997). El inconsciente óptico. Madrid: Tecnos.

Lebeer, I. (1997). L' art? C' est une meilleure ideé!:Entretiens, 1972-1984. Nimes: Jacqueline Chambon. 
Loup Sougez, M. (1998). Historia de la fotografía. Madrid: Cátedra.

Mah, S. (2010). El tiempo expandido. En VV. AA: El tiempo expandido. PhotoEspaña. Madrid: La Fábrica Editorial.

Mira Pastor, E. (2015). Tiempo y narratividad en la fotografía: de la paradoja al campo expandido. En Fotocinema. Revista Científica de Cine y Fotografia, $\quad \mathrm{n}^{\mathrm{o}} \quad 16, \quad$ pp. 6-80. Disponible: http://www.revistafotocinema.com/

Moholy-Nagy, L. (2015). Pintura, fotografía, cine y otros escritos sobre fotografía. Barcelona: Gustavo Gili.

Pallasmaa, J. (2006). Los ojos de la piel. La arquitectura y los sentidos. Barcelona: Gustavo Gili.

Pierce, C. S. (1987). Obra lógico semiótica. Madrid: Taurus.

Souriau, É. (1986). La correspondencia de las artes. México: Fondo de Cultura Económica.

Stelzer, O. (1981). Arte y fotografía. Contactos, influencias y efectos. Barcelona: Gustavo Gili.

Stoichita, V. (2005). Ver y no ver. la tematización de la mirada en la pintura impresionista. Madrid: Siruela.

Sylvester, D. (2009). La brutalidad de los hechos. Entrevistas con Francis Bacon. Barcelona: Ediciones Polígrafa.

Virilio, P. (1988). Estética de la desaparición. Barcelona: Anagrama.

Werner Holzwarth, H. (ed.) (2008). Wolfwgang Tillmans. En Art Now vol. III, Köln: Taschen. 